\title{
Convulsions May Alter the Specificity of Kappa-Opiate Receptors
}

\author{
ALFRED MANSOUR AND ElLiot S. VALENSTEIN \\ Department of Psychology and Neuroscience Laboratory. The University \\ of Michigan, Ann Arbor. Michigan 48109
}

Received September 26, 1985; revision received January 21, 1986

\begin{abstract}
Morphine, a mu-opiate agonist, and ethylketazocine, a kappa-opiate agonist, produce distinct behavioral, pharmacologic, and biochemical effects. In the mouse, large doses of morphine produce convulsions that are usually lethal and that cannot be blocked by naltrexone, whereas ethylketazocine produces nonlethal clonic convulsions that can be blocked by naltrexone. Moreover, mice made tolerant to morphine failed to show cross-tolerance to ethylketazocine, suggesting that the convulsions induced by these drugs are not mediated via a common opioid mechanism. Following a series of electroconvulsive shocks, both morphine and ethylketazocine produced clonic convulsions that were not lethal and that could be blocked by naltrexone. Furthermore, electroconvulsive shock-treated animals made tolerant to morphine-induced convulsions showed cross-tolerance to ethylketazocine. These data suggest that eletroconvulsive shock may alter kappa-opioid systems in such a way as to allow mu-agonists to be functional at these sites. c) 1986 Academic Press, Inc.
\end{abstract}

\section{INTRODUCTION}

Opiate receptor multiplicity is at present a well accepted concept in opiate pharmacology. It was introduced by Martin and his colleagues $(9,21)$ and was based in part, on the various behavioral syndromes induced by narcotic analgesics in the chronic spinal dog. Morphine-like compounds (mu-receptor agonists) produced miosis, bradycardia, hypothermia, and a general depression of pain responses. Ethylketazocine (EKC)-like compounds (kappa-receptor agonists) produced depression of the flexor reflex and sedation, but did not markedly alter pulse and respiration rate, body temperature, and skin twitch reflex. Further, morphine tolerance did not result in cross-tolerance to EKC, and EKC-like compounds failed to suppress signs of abstinence in the mor-

Abbreviations: ECS-electroconvulsive shock, EKC—ethylketazocine. 
phine-dependent dog, again suggesting that morphine and EKC mediate their effects via different mechanisms.

Those early findings were bolstered by more recent studies using other experimental animals or protocols. Tepper and Woods (28) demonstrated that whereas morphine produced a Straub-tail response and a dose-dependent increase in locomotor activity in the mouse, EKC failed to produce a Straubtail response and induced a decrease in locomotion. Moreover, the induction of tolerance to EKC's locomotor depressing effect did not result in crosstolerance to morphine, indicating that the locomotor changes induced by these compounds are mediated by different mechanisms. Hein et al. (11) reported that EKC and morphine have different discriminative effects, as monkeys trained to discriminate EKC from saline showed drug-appropriate responding to other kappa-agonists, but failed to generalize to morphine, levorphanol, or codeine. Woods et al. (35) also dissociated EKC and morphine using the self-administration paradigm. They found that monkeys self-administered morphine-like drugs, but failed to self-administer EKC at rates above those maintained by saline. And finally, although both mu and kappa compounds produce analgesia, their sites of action in the nervous system have been shown to differ (34). Injections of mu-agonists in the periaquaductal grey produce analgesia, whereas similar injections of EKC do not. EKC was found to induce analgesia, however, when injected directly into the spinal cord.

In addition to these findings, we recently found that mu- and kappa-agonists produce convulsions via different mechanisms in the mouse (20). Mu-agonists produced convulsions only at lethal doses, could not be blocked by naltrexone, and their order of potency was not consistent with established opiate receptor responses. Codeine was found to be more potent than morphine and levorphanol failed to produce convulsions even at lethal doses. In contrast, studies using such endpoints as analgesia and locomotion consistently report that the descending order of potency is levorphanol, morphine, and codeine $(25,29)$. Kappa-agonists (EKC and UM 1071), on the other hand, produced clonic convulsions that were not lethal, that could be blocked by naltrexone, and that were stereoselective. These findings suggested that the convulsions observed with mu-opiates may not be mediated by opiate receptors, and those induced by kappa-agonists appear to be a receptor-specific response.

Following a series of electroconvulsive shocks (ECS) we found that animals showed a marked change in responsiveness to mu- and kappa-agonists (1820). In contrast to the effects observed in normal animals, both mu- and kappa-agonists produced receptor-specific convulsions. In ECS-treated animals, both mu and kappa compounds produced nonlethal, naltrexone antagonizable, clonic convulsions at significantly smaller doses than in normal animals. In addition, the relative effectiveness of mu-agonists was consistent 
with other opiate responses; levorphanol was most potent followed by morphine and codeine. These results suggested that although mu- and kappaagonists produce their convulsant effects via different mechanisms in normal mice, they may induce convulsions via a common opioid mechanism following ECS. To test this possibility, we examined whether or not the induction of morphine tolerance results in cross-tolerance to EKC's convulsant effects in ECS-treated and normal animals. The appearance of cross-tolerance would indicate a common mechanism of action, and the lack of cross-tolerance would suggest independent mechanisms.

We also extended our previous findings by examining the change in opiate responsiveness during the development of seizure proneness. Several reports have suggested that endogenous opioids are released either after or during seizure activity $(13,14,16,24,26,30-32)$. It is possible, then, that a periodic release of opioids in association with seizures may be necessary for the induction of seizure proneness or kindling. We tested this hypothesis by treating animals with daily subconvulsive doses of EKC, morphine, or codeine to determine if normal animals would become sensitized to the convulsant effects of drugs. We characterized the convulsions produced by this procedure further by examining whether or not they are reversible by naltrexone and represent an cnduring change in functioning.

\section{METHODS}

General Methods. All animals used were adult male C57BL/6J mice either bought from Jackson Laboratories, Bar Harbor, Maine, or bred in our laboratory from Jackson laboratory stock. The animals were maintained on a 12-h light:12-h dark cycle (lights on at $2200 \mathrm{~h}$ ) with food and water available ad libitum. All drug data points were based on a minimum of six animals that were randomly assigned to each drug condition. The animals were injected i.p. and the range of doses was based on the results from pilot experiments. The percentage of animals showing a generalized convulsion, including clonic limb movements and falling, was recorded for each condition and was used as the dependent variable in each of the experiments.

The ECS-treated animals received seven daily electroconvulsive shocks and were tested at various times after their last convulsion. The ECS procedure consisted of passing electricity to the cornea $(6.5 \mathrm{~mA}, 0.5 \mathrm{~s})$ via two salinesoaked gauze pads that were attached to two wooden dowels.

Experiment I. Morphine Tolerance and Cross-Tolerance to Ethylketazocine in Electroconvulsive-Shock-Treated and Normal Animals. Normal mice. Morphine tolerance was induced in a group $(N=19)$ of normal mice by injecting them three times daily $(900,1700$, and $2400 \mathrm{~h})$ with $100 \mathrm{mg} / \mathrm{kg}$ morphine for 3 days. On their 4 th day of treatment, they were injected with $100 \mathrm{mg} / \mathrm{kg}$ morphine $(900 \mathrm{~h})$ and tested with EKC $(3.0,6.0$, or $10.0 \mathrm{mg} / \mathrm{kg}) 4$ to $6 \mathrm{~h}$ 
later to examine if they were cross-tolerant. A separate group $(N=19)$ of animals received the same schedule of saline injections and were similarly tested with EKC $(3.0,6.0$, or $10.0 \mathrm{mg} / \mathrm{kg})$. The percentage of animals convulsing to EKC was recorded during a 30-min observation period.

An additional two groups $(N=12$ or 14) of normal mice were treated with chronic administration of morphine $(100 \mathrm{mg} / \mathrm{kg})$ or saline according to the schedule described above and tested with morphine $(300$ or $600 \mathrm{mg} / \mathrm{kg}$ ) to examine whether or not the induction of morphine tolerance would alter an animal's sensitivity to the convulsant effects of morphine. The percentage of animals convulsing to morphine ( 300 or $600 \mathrm{mg} / \mathrm{kg}$ ) was recorded during a 120-min test period.

Electroconvulsive shock-treated mice. One day after their last of seven convulsions, ECS-treated animals $(N=26)$ received morphine injections twice daily $(1000$ and $1500 \mathrm{~h}$ ). The animals initially received an injection of 30 $\mathrm{mg} / \mathrm{kg}$ morphine and were thereafter treated with doses of $100 \mathrm{mg} / \mathrm{kg}$ morphine. After each injection, the animals were observed and the percentage of animals convulsing was recorded during a 90-min test period. ECS-treated animals were considered to be tolerant when none convulsed to morphine $(100 \mathrm{mg} / \mathrm{kg})$ during two consecutive test periods. This criterion was reached after the sixth morphine injection. A second group $(N=18)$ of ECS-treated animals were similarly handled and treated with six saline injections.

The morphine-treated ECS animals were tested the following day with one of several doses of EKC $(3.0,10.0$, or $30.0 \mathrm{mg} / \mathrm{kg})$ to determine whether or not morphine tolerance would result in cross-tolerance to EKC. The salinetreated ECS mice were similarly treated with $1.0,1.7$, or $3.0 \mathrm{mg} / \mathrm{kg} \mathrm{EKC.}$ The percentage of animals convulsing to EKC was recorded during a 30-min test period.

Recovery. The morphine-and saline-treated ECS animals were injected again with $\operatorname{EKC}(1.0,1.7$, or $3.0 \mathrm{mg} / \mathrm{kg}) 7$ days after their cross-tolerance testing. The percentage of animals convulsing was recorded for $30 \mathrm{~min}$ following their injection. Three days later, the animals in both treatment groups were tested with morphine $(10.0,30.0$, or $100.0 \mathrm{mg} / \mathrm{kg})$ and observed for convulsions during a 90 -min test period.

Metrazol control. Because morphine-treated ECS animals showed crosstolerance to $\mathrm{EKC}$, we examined if these effects were due to a general decreased sensitivity to convulsant drugs. An additional two groups $(N=21$ or 18$)$ of mice received seven ECS and treated with six injections of morhpine or saline in accordance with the drug schedule described for electroshocked mice. The morphine- and saline-treated ECS animals were tested the following day with one of several doses of metrazol $(35.0,40.0$, or $45.0 \mathrm{mg} / \mathrm{kg})$ and observed for convulsions during a 30 -min test period. 
Experiment II. Repeated Opiate Administration and Seizure Proneness. Five groups ( $N=7$ or 8 ) of mice received daily injections of either mu (morphine, codeine)- or kappa (EKC)-opiates and were observed for convulsions. Groups I and II were injected for 20 days with either 100 or $170 \mathrm{mg} / \mathrm{kg}$ codeine, respectively, and were observed for $30 \mathrm{~min}$. Groups III and IV were injected with either 100 or $300 \mathrm{mg} / \mathrm{kg}$ morphine, respectively, and were observed for $90 \mathrm{~min}$. Group III's drug treatment was extended to 31 days because one animal in this group started to convulse after receiving its 20th dose of morphine $(100 \mathrm{mg} / \mathrm{kg})$. Group IV was treated with morphine $(300 \mathrm{mg} / \mathrm{kg})$ for 20 days. Group V was injected with EKC ( $3 \mathrm{mg} / \mathrm{kg})$ for 19 days and was observed for a 30-min test period. These doses of opiates were chosen because they had been found to produce convulsions in less than $20 \%$ of the normal animals (20) thereby providing a low baseline to test whether or not sensitization occurs. The length of the observation period was determined by previous pilot data which indicated that convulsions did not occur beyond these time periods.

As only repeated EKC administration resulted in a sensitization or kindling effect, we tested whether or not the EKC-induced convulsions were a receptormediated response and could be blocked by naltrexone pretreatment. The animals previously kindled with EKC were treated with either saline or naltrexone $(0.1,0.3,1.0$, and $3.0 \mathrm{mg} / \mathrm{kg})$ on the alternate days $5 \mathrm{~min}$ prior to receiving EKC ( $3 \mathrm{mg} / \mathrm{kg}$ ). This drug testing protocol took 8 days to complete (days 20 to 27). To examine whether or not the enhanced seizure proneness observed with EKC was "permanent" as has been described with electrical kindling (10), the EKC-treated animals were tested again with EKC $(3 \mathrm{mg}$ / kg) 30 (day 57) and 90 (day 117) days after the last naltrexone and FKC injection.

\section{RESULTS}

Experiment I. ECS animals receiving repeated doses of morphine showed tolerance to its convulsant effects (Fig. 1). Whereas $85 \%$ of the ECS animals convulsed following their first $100-\mathrm{mg} / \mathrm{kg}$ injection of morphine, none convulsed after their fourth or fifth injection at this dose $\left(\chi^{2} 38.13, P<0.01\right)$. If circadian variation in morphine sensitivity is taken into account by comparing those injections administered at the same time in the light-dark cycle (injections $1,3,5$ or $2,4,6$ ), one observes a gradual decline in the percentage of animals convulsing. In contrast, chronic morphine treatment failed to significantly alter the morphine-induced convulsion dose-response curve in normal animals ( $\chi^{2} 2.4$ at $300 \mathrm{mg} / \mathrm{kg}$ morphine, $\chi^{2} 1.66$ at $600 \mathrm{mg} / \mathrm{kg}$ morphine, both n.s.). 
Morphine-tolerant ECS mice showed cross-tolerance to EKC (Fig. 2, left). Whereas $84 \%$ of the saline-treated ECS animals convulsed to a $3-\mathrm{mg} / \mathrm{kg}$ dose of EKC, none of the morphine-treated ECS animals convulsed at this dose $\left(\chi^{2} 10.37, P<0.01\right)$. Even doses as high as $30 \mathrm{mg} / \mathrm{kg}$ EKC produced convulsions in only $40 \%$ of the morphine-tolerant ECS animals. In contrast, normal animals who have been made tolerant to morphine failed to show cross-tolerance to EKC (Fig. 2, right). In fact, the data suggest that morphinetolerant mice were more sensitive to EKC's convulsant effect $\left(\chi^{2} 8.57, P\right.$ $<0.01$ at $6 \mathrm{mg} / \mathrm{kg}$ ).

The morphine-treated ECS animals showed a complete recovery to EKC 7 days following their cross-tolerance testing. They also recovered their sensitivity to morphine and did not differ from saline controls in their responsiveness to morphine when tested 3 days later. The cross-tolerance was not due to a general decreased sensitivity to convulsants as morphine-tolerant ECS animals were not less sensitive to metrazol (Fig. 3).

Experiment II. Of animals treated with subconvulsive doses of morphine, codeine, or EKC, only those treated with EKC showed a robust kindling effect (Fig. 4). The percentage of animals convulsing to EKC gradually increased with daily administration and was at its maximum level after 13 injections. Although none of the animals convulsed to the first injection of EKC $(3 \mathrm{mg} /$ $\mathrm{kg}), 86 \%$ of them convulsed after their 13th injection. The convulsions kindled with EKC appear to be receptor-mediated as they could be completely blocked

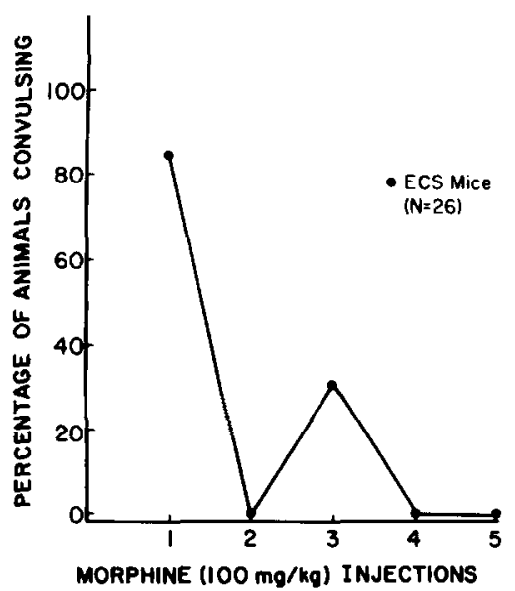

FIG. 1. Percentage of electroconvulsive shock-treated (ECS) mice convulsing to morphine administered twice daily. The animals were initially treated with $30 \mathrm{mg} / \mathrm{kg}$ morphine and thereafter injected with a dose of $100 \mathrm{mg} / \mathrm{kg}$ (injections 1 to 5). 

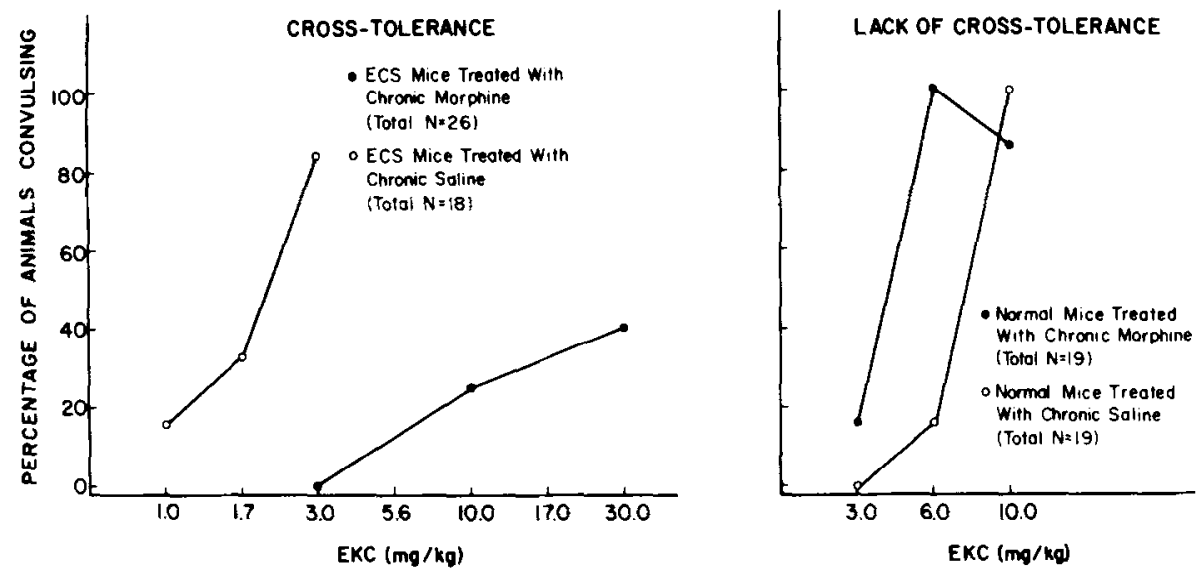

FIG. 2. Percentage of morphine-tolerant and saline-treated ECS and normal animals convulsing to ethylketazocine (EKC). All data points were based on six or more animals.

by naltrexone $(3 \mathrm{mg} / \mathrm{kg})$ pretreatment $\left(\chi^{2} 7.78, P<0.01\right)$. Further, this change in sensitivity to EKC seems to be "permanent" as animals tested at 1 month (six of seven animals convulsed) and 3 months (five of six animals convulsed) still showed the effect. In contrast, repeated daily injections of morphine $(100$ or $300 \mathrm{mg} / \mathrm{kg}$ ) failed to produce a kindling effect; only two of eight animals treated with $300 \mathrm{mg} / \mathrm{kg}$ and one of seven animals treated with $100 \mathrm{mg} / \mathrm{kg}$ morphine convulsed during this treatment protocol. Similarly, daily injections of codeine failed to produce a kindling effect, as none of the animals treated

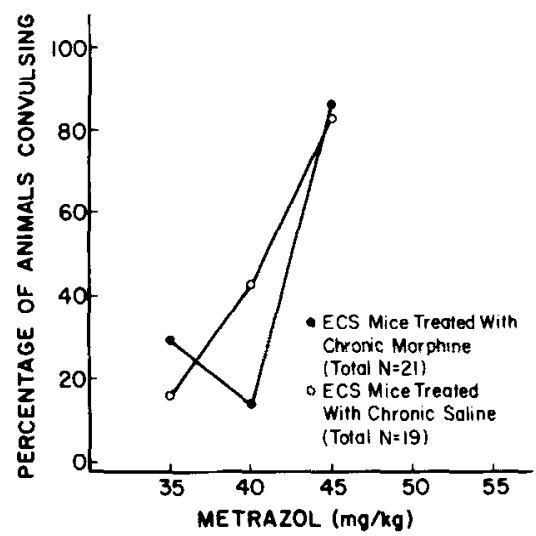

FIG. 3. Percentage of morphine-tolerant and saline-treated FCS mice convulsing to metrazol. All data points were based on six or more animals. 


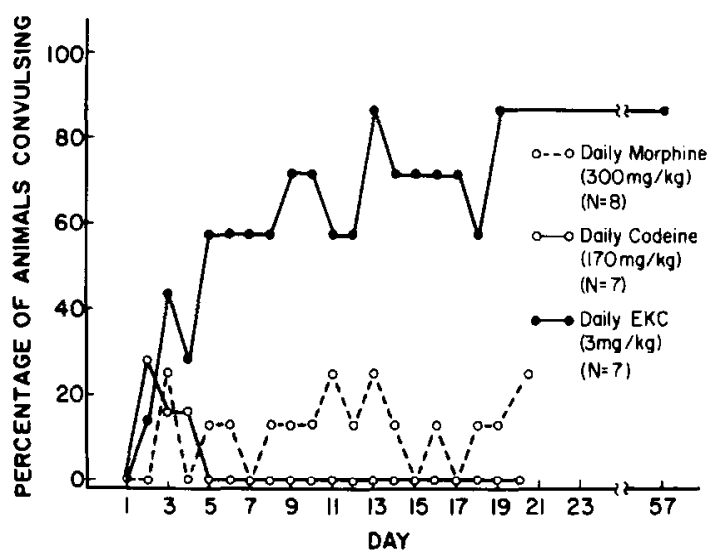

FIG. 4. Percentage of normal mice convulsing to daily doses of morphine, codeine, or EKC. Lower doses of morphine $(100 \mathrm{mg} / \mathrm{kg})$ and codeine $(100 \mathrm{mg} / \mathrm{kg})$ were also administered daily to separate groups of mice. Because these smaller doses failed to produce a kindling effect, they were not included in the figure.

with $100 \mathrm{mg} / \mathrm{kg}$ convulsed after 20 days of injections and only 2 of 7 convulsed with $170 \mathrm{mg} / \mathrm{kg}$. Of the 2 animals that convulsed with codeine, one died during its first convulsion and the other died after its third convulsion.

\section{DISCUSSION}

These data suggest that morphine and EKC produce their convulsant effects by different mechanisms in naive animals, but function through a common opioid mechanism following the induction of convulsions. This conclusion is supported by the finding of a morphine-EKC cross-tolerance in ECS-treated mice and not in normal animals. In addition, as our work demonstrates (1820 ), the convulsions induced by mu-opiates in normal animals are not receptor-mediated, whereas those observed to follow ECS are receptor-specific. In normal mice, mu-agonists produce convulsions that are not reversible by naltrexone, usually lethal, and not altered by chronic morphine treatment. These findings are consistent with the report (22) that rats receiving repeated large systemic doses of morphine do not become tolerant to its seizure-inducing effects. In contrast, following ECS, mu-agonists induce convulsions that are nonlethal, reversible by naltrexone, and demonstrate tolerance and crosstolerance to other opioids. Kappa-agonists, on the other hand, induce convulsions by an opioid receptor mechanism in both ECS and normal mice.

The ability of naloxone or naltrexone to antagonize the convulsions induced by systemically administered mu-opioids remains a point of controversy in 
the literature. Several reports have indicated that these convulsions are not antagonizable $(15,27)$, whereas others report that they can be blocked by opiate antagonists $(1,8)$. Undoubtedly, these results are likely to be due to species and procedural differences. However, it has been our experience that systemically administered mu-opiates have either not produced convulsions in normal mice or have produced convulsions that could not be blocked by pretreatment with an opiate antagonist.

The question arises, then, as to how morphine and other mu-agonists which do not produce convulsions by an opiate receptor mechanism in normal animals, do so following ECS. One possible explanation is that ECS alters the selectivity of kappa-receptors in such a way as to allow mu agonists to be functional at these receptors. Several lines of evidence support this hypothesis. First, both mu- and kappa-agonists produce convulsions in ECS-treated animals that can be blocked by similar doses of naltrexone (1 to $3 \mathrm{mg} / \mathrm{kg}$ ). Reversal of kappa-receptor-mediated effects characteristically requires substantially larger doses of naloxone or naltrexone than required to reverse mureceptor-mediated responses. Our finding that naltrexone was equally effective in blocking the convulsions induced by mu- and kappa-opiates argues for a common opiate mechanism of action. Second, although agonists, such as morphine, show a relative selectivity for mu-receptors, they have a substantial affinity for the kappa-receptor as well (17). In fact, the order of potency of mu-agonists observed in ECS-treated animals (levorphanol $>$ morphine $>$ codeine) is consistent with their affinity for kappa-receptors. Levorphanol was found to have greater affinity for kappa-receptors than morphine, which is well correlated with its greater effectiveness in inducing convulsions in ECS animals. And third, as the present study demonstrates, ECS animals made tolerant to morphine show cross-tolerance to EKC's convulsant effects. The cross-tolerance observed was not due to an inherent difference between the morphine- and saline-treated animals in their sensitivity to EKC and morphine prior to initiating drug treatment, as the groups did not differ after a 1-week recovery period. In addition, the cross-tolerance observed can not be explained on the basis of a general decreased sensitivity to convulsants, as morphinetolerant ECS animals were not less sensitive to metrazol.

The convulsant actions of EKC and morphine can be dissociated further in normal animals when administered daily. Of animals treated with daily subconvulsive doses of $\mathrm{EKC}$, morphine, or codeine, only those animals treated with EKC showed a robust kindling effect. The EKC-kindled convulsions appeared to be a specific response as they could be blocked by naltrexone. Further, as seen with amygdala kindling, the change in sensitivity appears to be "permanent" as animals remained sensitized to EKC for at least 3 months. Whereas other investigators have suggested that morphine's locomotor effect 
in the mouse, an opiate receptor-mediated response, shows signs of sensitization with repeated daily administration [for review, see (23)], our evidence demonstrates that this is not the case for morphine's convulsant effect and suggests that the two effects may be mediated by different mechanisms.

It is conceivable, therefore, especially in view of the epileptogenic properties of the endogenous opioids $(4,6,7,12,33)$ and the fact that their concentrations are elevated following a series of convulsions $(13,14,16,32)$, that they may play a role in the sensitization observed with the induction of convulsions. Elevation in the concentrations of dynorphin, an endogenous opioid peptide with a strong affinity for kappa-receptors $(2,3)$, following the completion of amygdala kindling (24) is particularly interesting in light of our data with EKC. These changes in dynorphin content persisted for at least 1 month following an animal's last convulsion.

It should be noted that the effects we observed with systemic administration of opiates are different from those observed with intraventricular injections. The seizure-inducing effects of morphine and endogenous opioid peptides observed in normal animals to follow intraventricular injections appear to be a specific receptor response. In contrast to systemic injections, intraventricular injections of morphine or opioid peptides produce seizures that are naloxonereversible, show tolerance with repeated administration, and are not observed in morphine-tolerant animals [for review, see (5)]. These differences may be due to morphine's different site(s) of action when systemic or intraventricular routes are used.

\section{REFERENCES}

1. Chapman, J. E., and E. J. Walazek. 1962. Antagonism of some toxic effects of dextropropoxyphene by naloxphine. Toxicol. Appl. Pharmacol. 4: 752-758.

2. ChAVKIN, C., I. JAMES, AND A. GoldSTEIN. 1982. Dynorphin is a specific endogenous ligand of the kappa opioid receptor. Science 215: 413-415.

3. Corbett, A., S. J. Paterson, A. T. MCKNiGht, J. Magnan, and H. W. Kosterlitz. 1982. Dynorphin (1-8) and dynorphin (1-9) are ligands for the kappa subtype of opiate receptor. Nature 299: 79-81.

4. Elazar, Z., R. Simantov, and E. Motles. 1982. Local electrographic effects of Leu-enkephalin microinjections into the brain. Electroenceph. Clin. Neurophysiol. 54: 91-95.

5. FRENK, H. 1983. Pro- and anticonvulsant actions of morphine and the endogenous opioids: involvement and interactions of multiple opiate and non-opiate systems. Brain Res. Rev. 6: $197-210$.

6. FRENK, H., B. C. MCCARTY, AND J. C. LIEBESKIND. 1978. Different brain areas mediate the analgesic and epileptic properties of enkephalin. Science 200: 335-337.

7. Frenk, H., G. URCA, AND J. C. Liebeskind. 1978. Epileptic properties of leucine- and methionine-enkephalin: comparison with morphine and reversibility by naloxone. Brain Res. 147: 327-337.

8. Gilbert, P. E., AND W. R. MARTIN. 1975. Antagonism of the convulsant effects of heroin, 
D-propoxyphene, meperidine, normeperidine, and thebaine by naloxone in mice. $J$. Pharmacol. Exp. Ther. 192: 538-541.

9. Gilbert, P. E., AND W. R. MARTIN. 1976. The effects of morphine-and nalorphine-like drugs in the nondependent, morphine-dependent and cyclazocine-dependent chronic spinal dog. J. Pharmacol. Exp. Ther. 198: 66-82.

10. GODDARD, G. V., D. C. MCINTYRE, AND C. K. LEECH. 1969. A permanent change in brain function resulting from daily electrical stimulation. Exp. Neurol. 25: 295-330.

11. Hein, D. W., A. M. Young, S. Herling, AND J. H. WoOdS. 1981. Pharmacological analysis of the discriminative stimulus characteristics of ethylketazocine in the rhesus monkey. $J$. Pharmacol. Exp. Ther. 218: 7-15.

12. HeNRIKSEN, S. J., F. E. BloOM, F. MCCOY, N. LiNG, AND R. GuILlemin. 1978. $\beta$-Endorphin induces nonconvulsive limbic seizures. Proc. Natl. Acad. Sci. U.S.A. 75: 5221-5225.

13. Hong, J. S., P. L. WoOd, J. C. Gillan, H. Y. T. YANG, AND E. Costa. 1980. Changes of hippocampal met-enkephalin content after recurrent motor seizures. Nature 285: 231232.

14. Kato, N., T. Higuchi, H. G. Friesen, and J. A. Wada. 1983. Changes of immunoreactive somatostatin and $\beta$-endorphin content in rat brain after amygdaloid kindling. Life Sci. 32: $2415-2422$.

15. KOPPaNY, T., AND A. G. KaRCZMAR. 1953. Nature of antagonism between $N$-allyl-normorphine (Nalline) and morphine. Fed. Proc. 12: 337.

16. Lason, W., B. Przewlocka, L. Stala, AND R. Przewlocki. 1983. Changes in hippocampal immunoreactive dynorphin and neoendorphin content following intra-amygdalar kainic acid-induced seizures. Neuropeptides 3: 399-404.

17. Magnan, J., S. J. Paterson, A. Tavanti, and H. W. Korterlitz. 1982. The binding spectum of narcotic analgesic drugs with different agonist and antagonist properties. NauynSchmiedeberg's Arch. Pharmacol. 319: 197-205.

18. Mansour, A., R. Doyle, R. KaTz, AND E. S. Valenstein. 1981. Long-lasting changes in morphine sensitivity following amygdaloid kindling in mice. Physio. Behav. 27: 11171120.

19. Mansour, A., And E. S. Valenstein. 1984. Morphine sensitivity and seizure proneness. Exp. Neurol. 85: 346-357.

20. Mansour, A., AND E. S. Valenstein. 1985. Changes in responsiveness to mu and kappa opiates following a series of convulsions. Exp. Neurol. 90: 224-237.

21. Martin, W. R., C. G. Eades, J. A. Thompson, R. E. Huppler, and P. E. Gilbert. 1976. The effects of morphine- and nalorphine-like drugs in the nondependent and morphinedependent chronic spinal dog. J. Pharmacol. Exp. Ther. 197: 517-532.

22. PinSKy, C., A. K. Ova, AND F. S. Labella. 1982. Peptidase inhibitors reduce opiate narcotic withdrawal signs, including seizure activity, in the rat. Brain Res. 243: 301-307.

23. Post, R. M. 1980. Intermittent versus continuous stimulation: effect of time interval on the development of sensitization or tolerance. Life Sci. 26: 1275-1282.

24. PrzeWlocki, R., W. Lason, R. StaCh, AND D. KaCZ. 1983. Opioid peptides, particularly dynorphin, after amygdaloid-kindled seizures. Regul. Pep. 6: 385-392.

25. ReThy, C. R., C. B. SMITH, AND J. E. VILLARREAL. 1971. Effects of narcotic analgesics upon the locomotor activity and brain catecholamine content of the mouse. J. Pharmacol. Exp. Ther. 176: 472-479.

26. Sarne, Y., B. A. WeisSman, and G. URCA. 1982. Differential effects of long-term electroconvulsive shock and brain levels of enkephalin and humoral-endorphin. $J$. Neurochem. 39: $1478-1480$. 
27. Snyder, E. W., D. E. Shearer, E. C. Beck, ANd R. E. Dustman. 1980. Naloxone-induced electrographic seizures in the primate. Psychopharmacology 67: 211-214.

28. TEPPER, P., AND J. H. WOODS. 1978. Changes in locomotor activity and naloxone-induced jumpings in mice produced by WIN 35, 197-2 (ethylketazocine) and morphine. Psychopharmacology 58: 125-129.

29. TERENIUS, L. 1974. Contribution of "receptor" affinity to analgesia potency. Comm. J. Pharm. Pharmacol. 26: 146-148.

30. Vindrola, O., M. ASaI, M. Zubieta, AND G. Linares. 1983. Brain content of immunoreactive leu-enkephalin and met-enkephalin after pentylenetrazol-induced convulsions. Eur. J. Pharmacol. 90: 85-89.

31. Vindrola, O., R., Briones, M. ASAl, AND A. FernandeZ-Guardiola. 1981. Amygdaloid kindling enhances the enkephalin content in the rat brain. Neurosci. Lett. 21: 39-43.

32. Vindrola, O., R. BRIONES, M. ASAI, AND A. FernandeZ-Guardiola. 1981. Brain content of leu- and met-enkephalin changes independently during the development of kindling in the rat. Neurosci. Lett. 26: 125-130.

33. Walker, J. M., H. C. MoISES, D. H. COY, G. BALDRIGHI, AND H. AKIL. 1982. Nonopiate effects of dynorphin and des-tyr-dynorphin. Science 218: 1136-1138.

34. WOOD, P. L., A. RACKHAM, AND J. RICHARD. 1981. Spinal analgesia: comparison of the mu agonist morphine and kappa agonist ethylketazocine. Life Sci. 28: 2119-2125.

35. Woods, J. H., C. B. SMIth, F. MEdzihradSky, AND H. H. Swain. 1979. Preclinical testing of new analgesic drugs. Pages $429-445$ in R. F. BEERS, JR. AND E. G. BASSETT, Eds., Mechanisms of Pain and Analgesic Compounds. Raven Press, New York. 